\title{
Case Report \\ Henoch-Schonlein Purpura Successfully Treated with Dexamethasone: A Case Report of Six-year- old Female
}

\author{
Purushottam Adhikari \\ Department of Medicine, Gandaki Medical College, Nepal \\ Address for correspondence: Purushottam Adhikari, Department of Medicine, Gandaki Medical \\ College, Nepal. E-mail: puru.ad12@gmail.com
}

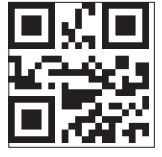

Quick Access Code

How to cite this article: Adhikari P. HenochSchonlein Purpura Successfully Treated with Dexamethasone: A Case Report of Sixyear-old Female. Journal of Medical Research and Innovation.

2018;2(1):e000095.

Doi: $10.15419 /$ jmri.95.

Publication history: Received: 29/09/2017

Accepted: 01/11/2017

Published: 01/11/2017

Editor: Dr. Surya Parajuli

Copyright: Adhikari P. This $s$ an open access article distributed under the terms of the Creative Commons Attribution License CC-BY 4.0., which permits unrestricted use, distribution, and reproduction in any medium, providead the original author and source are credited.

Funding: NIL Conflict of Interest: NIL

\begin{abstract}
Henoch-Schonlein Purpura (HSP) is one of the most common causes of small vessel vasculitis in children. A 6-year-old female presented with abdominal pain, swelling, and rashes over both the legs associated with multiple episodes of vomiting for around 10 days. Stool for the occult blood test was positive, but there was an absence of hematuria and albuminuria. The case was diagnosed as HSP and treated with dexamethasone for 10 days. The patient was finally discharged on the resolution of her symptoms. Early diagnosis and treatment favor the better outcome in cases without any renal complications.
\end{abstract}

Keywords: Henoch-Schonlein Purpura, Vasculitis, Steroids, Dexamethasone

\section{Introduction}

Henoch-Schonlein Purpura (HSP), also known as IgA vasculitis, is a small vessel vasculitis with IgA1dominant immune deposits predominantly on capillaries, venules, or arterioles. It often involves skin and gastrointestinal system and may also cause arthritis. $^{[1]}$ It is commonly seen in children and characterized by palpable purpura more commonly located in the dependent body parts such as lower extremities and buttocks, arthritis/arthralgia, and bowel angina along with hematuria/proteinuria. ${ }^{[2]}$ The various etiologies have been suggested such as varieties of pathogens, drugs, and environmental exposure among which Group A beta-hemolytic Streptococcus has been much studied. ${ }^{[3]}$

The natural history of the disease has selflimiting course in most of the cases except that those of renal complications associated with it. Symptomatic treatment with nonsteroidal anti-inflammatory drugs along with the steroids will have the joint and abdominal pain relief. ${ }^{[4]}$ Corticosteroids if given in the early course of disease can help to provide a better clinical outcome. ${ }^{[5]}$ The prognosis is good, with exception of renal involvement that may need the follow-up till 6 months or longer. ${ }^{[6,7]}$
The exact prevalence of HSP in our settings has yet to be discovered, but various studies revealed it to be one of the important causes of childhood renal disease. ${ }^{[8,9]}$

\section{Case Report}

The case is reported after taking informed written consent from the patient's mother. 6 -year-old female presented with the complaints of pain in abdomen, swelling, and rashes over the lower limbs associated with multiple episodes of vomiting for 10 days. Pain in the abdomen was localized around the umbilicus and was sudden in onset, intermittent in nature, non-radiating, and alleviated on lying flat on the bed. She developed swelling in both legs subsequently a day after abdominal pain along with the appearance of rashes starting from feet and progressing to thigh and buttocks. She also developed three to four episodes of vomiting in last 5 days. The vomiting was non-projectile and non-blood stained.

On examination, the general condition of the patient was fair and vitals were stable. The abdomen was soft and non-tender. Mild bilateral 
non-pitting edema was present over both the legs. There was the presence of non-tender, non-blanching, purpuric rashes over both lower limbs, and extending up to the buttocks.

Laboratory tests showed leukocytosis with WBC count of $12,000 / \mathrm{mm}^{3}$; neutrophils: $8800 / \mathrm{mm}^{3}$; lymphocyte: $3200 /$ $\mathrm{mm}^{3}$; platelets: 4,22,000/ $\mathrm{mm}^{3}$; hemoglobin: $14 \mathrm{~g} / \mathrm{dl}$; ESR: $12 \mathrm{~mm} / 1^{\text {st }} \mathrm{h}$; serum urea: $33 \mathrm{mg} / \mathrm{dl}$; serum creatinine: $0.6 \mathrm{mg} /$ dl; sodium: $139 \mathrm{mmol} / \mathrm{l}$; potassium: $4.6 \mathrm{mmol} / \mathrm{l}$; CRP: $0.92 \mathrm{mg} / \mathrm{l}$; urinalysis: No hematuria or proteinuria, and stool analysis showed the presence of occult blood. The plain X-ray abdomen and ultrasound abdomen/pelvis revealed no abnormalities.

Diagnosis of HSP was made in accordance with the American College of Rheumatology and European League Against Rheumatism (EuLAR) and Pediatric Rheumatology Society (PReS) criteria. ${ }^{[10,11]}$

She was treated with dexamethasone $0.14 \mathrm{mg} / \mathrm{kg} /$ dose 4 times a day intravenously for 5 days continuously and then tapered to 3 times a day for 3 days following by 2 times a day for next 2 days.

The recovery from purpura and bilateral swelling of the legs was observed after treatment in the $2^{\text {nd }}$ and $3^{\text {rd }}$ week [Figures 1-3].

\section{Discussion}

Henoch-Schonlein Purpura (HSP) was first described by William Heberden in 1801. Later, Schonlein recognized the association between purpura and arthritis, whereas Henoch reported a case that also included gastrointestinal symptoms along with the renal involvement. ${ }^{[12]}$ HSP is the most common vasculitis of the children. Half among all the cases occur before the age of five and males are affected twice as common as females. ${ }^{[13]}$

The exact etiology and pathogenesis of HSP are yet to be determined. Seasonal variation has been related with a high prevalence rate in autumn and winter. ${ }^{[2]}$ However, the case described here was diagnosed in the spring season. It has also been proposed that various triggers such as bacterial and viral infections, vaccinations, drugs, and autoimmune mechanisms may result in the formation of an antigen and antibody complex and the deposition of such formed immune complex in the small vessels may activate the alternate complement pathway leading to neutrophil aggregation which results in inflammation and vasculitis. ${ }^{[14]}$ Among all, the preceding infection of $\beta$-hemolytic Streptococcus has been one of the most studied cases. The positive throat cultures, as well as increased titers of anti-streptolysin $\mathrm{O}$, have been often found in many patients. ${ }^{[3]}$ The evidence of prior infection has not been recorded in the present case.

The patient generally presents with the classic tetrad of rashes, polyarthralgia, abdominal pain, and renal disease. The non-

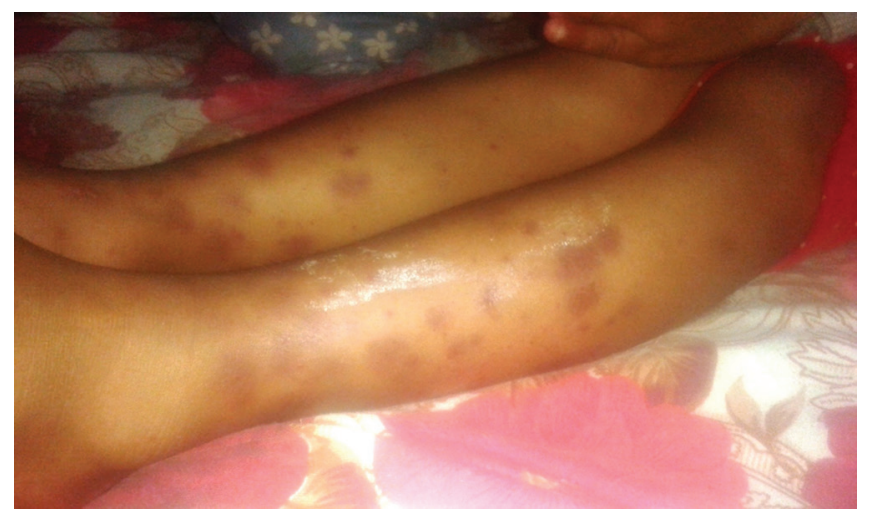

Figure 1: Purpura and swelling of bilateral lower limbs in the $1^{\text {st }}$ week

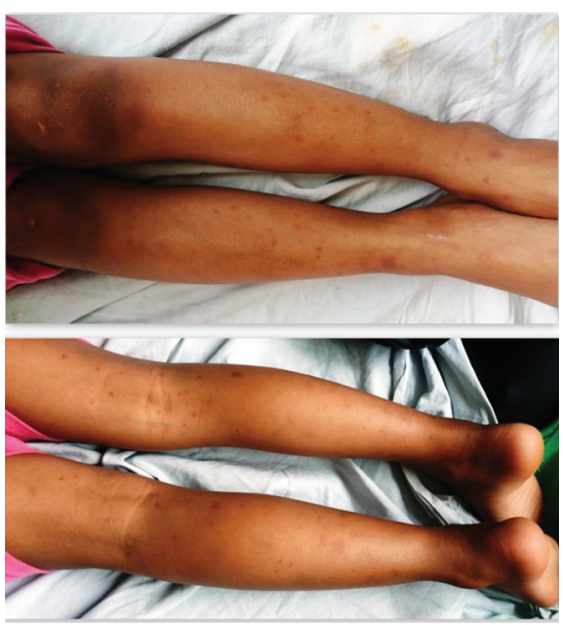

Figure 2: Progress of purpura in the $2^{\text {nd }}$ week after the admission of patient in hospital

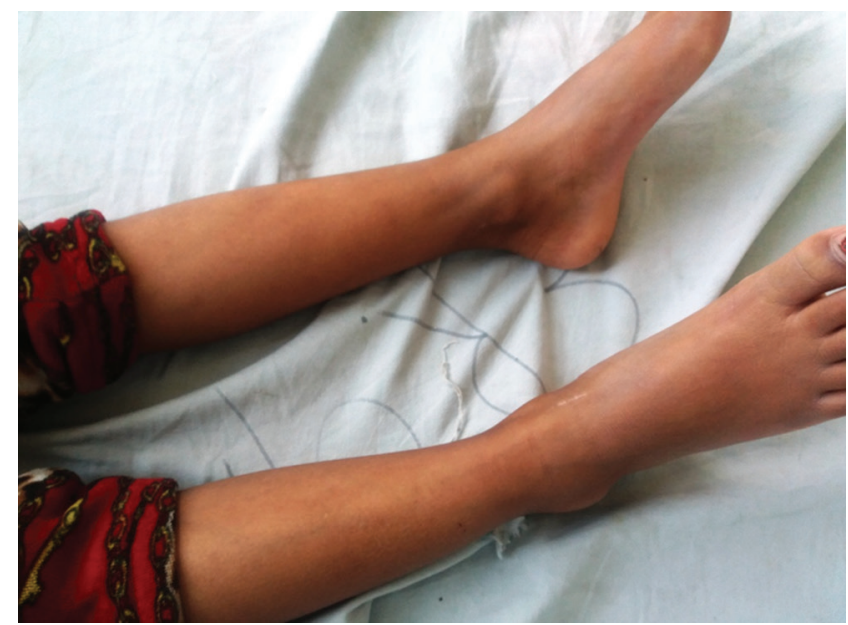

Figure 3: 3rd week before the discharge from hospital

blanching rashes clinically appear as a palpable purpura on the lower legs and arms. ${ }^{[13]}$ The joint involvement is generally characterized by the pain and swelling of the joints, most 
Table 1: The American College of Rheumatology - 1990 criteria for the diagnosis of HSP ${ }^{[10]}$

\begin{tabular}{ll} 
Criterion & Definition \\
\hline Palpable purpura & Slightly raised "palpable" hemorrhagic skin lesions, not related to thrombocytopenia \\
Age $<20$ at disease onset & Patient 20 years or younger at onset of first symptoms \\
Bowel angina & Diffuse abdominal pain, worse after meals, or the diagnosis of bowel ischemia, usually including bloody diarrhea \\
Wall granulocytes on biopsy & Histologic changes showing granulocytes in the walls of arterioles or venules \\
\hline
\end{tabular}

Table 2: EuLAR/PReS - 2006 criteria $^{[11]}$

\begin{tabular}{ll} 
Criteria & Definition \\
$\begin{array}{l}\text { Mandatory } \\
\text { criteria }\end{array}$ & Palpable purpura \\
$\begin{array}{l}\text { Additional } \\
\text { criteria }\end{array}$ & Diffuse abdominal pain \\
& $\begin{array}{l}\text { Any biopsy showing predominant IgA deposition } \\
\text { Arthritis or arthralgia } \\
\text { Renal involvement (any hematuria and/or } \\
\text { proteinuria) }\end{array}$ \\
\hline
\end{tabular}

affecting the knees and ankles. The abdominal pain followed by vomiting and intestinal bleeding is the dominant features involving the gastrointestinal system. Microscopic hematuria and albuminuria are the prominent renal findings. ${ }^{[5,15]}$

Our case had the symptoms of rashes over both lower legs, pain in abdomen, and vomiting. Joint involvement was absent. Significant laboratory finding was occult blood test positive in stool. However, there were no signs of hematuria and albuminuria.

The diagnosis of HSP was made by American College of Rheumatology-1990 criteria [Table 1] and EuLAR/PReS - 2006 criteria [Table 2].

The patient is said to have HSP if at least two of the four above criteria is present. In our case, there was the presence of palpable purpura, age $<20$ at disease onset and bowel angina, and thus was diagnosed as HSP.

The patient is said to have HSP if mandatory criteria are present along with at least one of the additional criteria. Our case fulfilled the mandatory criteria along with diffuse abdominal pain as the additional criteria.

There is a predominantly spontaneous resolution of all symptoms except that of the renal disease in the majority of the cases. Steroids are more often used for the relief of abdominal pain, joint pain, and skin disease. Alternatively, methotrexate and dapsone have been quite effective (steroidsparing agent) for the treatment of chronic abdominal pain and skin involvement. ${ }^{[4]}$ The role of the corticosteroids in preventing the long-term outcome of renal complications is controversial. A meta-analysis in the Medline database and the Cochrane
Controlled Trials Register based on a comprehensive review of the literature by Weiss et al. stated that early treatment with corticosteroid significantly reduces the odds of developing persistent renal disease along with surgical intervention and recurrence. ${ }^{[5]}$ In contrary, other trials and updates in the literature have mentioned that there is no long-term renal protective outcome on the early treatment with prednisolone. ${ }^{[16,17]}$

In general, prednisolone is the commonly used steroid for the treatment of HSP. Although in our case, we used dexamethasone, there is no evidence in literature to prove the superiority of one over another. Several cases and studies have been reported resulting in better outcomes on treatment with dexamethasone. ${ }^{[18,19]}$

The renal involvement has a high morbidity and mortality; otherwise, the disease has better prognosis. ${ }^{[7]} \mathrm{A}$ systematic review by Narchi stated that even if urinalysis is normal at the presentation, follow-up urine testing should be continued for at least 6 months as $97 \%$ children will develop abnormal urine findings by that time. ${ }^{[6]}$

Rarely, few cases of complicated HSP as intussusceptions, gastrointestinal bleeding and with cardiac involvement have been reported. ${ }^{[18,20,21]}$

\section{Conclusion}

HSP being one of the most common vasculitides of the children and its classic presentation of palpable purpura, arthritis, abdominal involvement, and renal features makes the diagnosis quite easier. Early initiation of treatment with steroids will help in symptomatic relief and bring a positive outcome. The renal disease may need long-term follow-up; otherwise, the diseases have favorable prognosis.

\section{Acknowledgment}

The author would like to acknowledge the patient's mother for providing consent for the case report. Furthermore, authors would like to thank to the faculty of the Department of Pediatrics, Gandaki Medical College, for their support, guidance, and suggestion during the course of study.

\section{References}

1. Jennette JC, Falk RJ, Bacon PA, Basu N, Cid MC, Ferrario F, et al. 2012 revised international chapel hill consensus 
conference nomenclature of vasculitides. Arthritis Rheum 2013;65:1-11.

2. Yang $\mathrm{YH}, \mathrm{Yu} \mathrm{HH}$, Chiang BL. The diagnosis and classification of Henoch-Schonlein purpura: An updated review. Autoimmun Rev 2014;13:355-8.

3. Saulsbury FT. Clinical update: Henoch-Schonlein purpura. Lancet (London, England) 2007;369:976-8.

4. Tizard EJ, Hamilton-Ayres MJ. Henoch schonlein purpura. Archives of disease in childhood Educ Pract Ed 2008;93:1-8.

5. Weiss PF, Feinstein JA, Luan X, Burnham JM, Feudtner C. Effects of corticosteroid on Henoch-Schonlein purpura: A systematic review. Pediatrics 2007;120:1079-87.

6. Narchi H. Risk of long term renal impairment and duration of follow up recommended for Henoch-Schönlein purpura with normal or minimal urinary findings: A systematic review. Arch Dis Child 2005;90:916-20.

7. Calvo-Rio V, Loricera J, Mata C, Martin L, Ortiz-Sanjuan F, Alvarez L, et al. Henoch-Schonlein purpura in northern Spain: Clinical spectrum of the disease in 417 patients from a single center. Medicine 2014;93:106-13.

8. Bhatta NK, Shrestha P, Budhathoki S, Kalakheti BK, Poudel P, Sinha $A$, et al. Profile of renal diseases in Nepalese children. Kathmandu Univ Med J (KUMJ) 2008;6:191-4.

9. Shah G. Clinical profile and pattern of Henoch-Schonlein purpura in children. J Patan Acad Health Sci 2015;2:17-21.

10. Mills JA, Michel BA, Bloch DA, Calabrese LH, Hunder GG, Arend WP, et al. The American college of rheumatology 1990 criteria for the classification of Henoch-Schonlein purpura. Arthritis Rheum 1990;33:1114-21.

11. Ozen S, Ruperto N, Dillon MJ, Bagga A, Barron K, Davin JC, et al. EULAR/PReS endorsed consensus criteria for the classification of childhood vasculitides. Ann Rheum Dis 2006;65:936-41.

12. Ballinger S. Henoch-Schonlein purpura. Curr Opin Rheum
2003;15:591-4.

13. Roberts PF, Waller TA, Brinker TM, Riffe IZ, Sayre JW, Bratton RL. Henoch-Schonlein purpura: A review article. South Med J 2007;100:821-4.

14. Sohagia AB, Gunturu SG, Tong TR, Hertan HI. Henochschonlein purpura-a case report and review of the literature. Gastroenterol Res Pract 2010;2010:597648.

15. Chen $O$, Zhu XB, Ren $P$, Wang YB, Sun RP, Wei DE. Henoch Schonlein purpura in children: Clinical analysis of 120 cases. Afr Health Sci 2013;13:94-9.

16. Dudley J, Smith G, Llewelyn-Edwards A, Bayliss K, Pike K, Tizard J. Randomised, double-blind, placebo-controlled trial to determine whether steroids reduce the incidence and severity of nephropathy in Henoch-Schonlein purpura (HSP). Arch Dis Child 2013;98:756-63.

17. Bluman J, Goldman RD. Henoch-Schönlein purpura in children: Limited benefit of corticosteroids. Can Fam Phys 2014;60:1007-10.

18. Seo MK, Hong J, Yim HE, Pai KS. A patient with HenochSchönlein purpura with intussusception and intractable nephritis. Child Kidney Dis 2016;20:92-6.

19. Shin JI, Lee SJ, Lee JS, Kim KH. Intravenous dexamethasone followed by oral prednisolone versus oral prednisolone in the treatment of childhood Henoch-Schonlein purpura. Rheumatol Int 2011;31:1429-32.

20. Yamazaki T, Akimoto T, Iwazu Y, Sugase T, Takeshima E, Numata $A$, et al. Henoch-Schonlein purpura complicated with severe gastrointestinal bleeding. CEN Case Rep 2015;4:106-11.

21. Lutz HH, Ackermann T, Krombach GA, Grone HJ, Rauen T, Floege J, et al. Henoch-Schonlein purpura complicated by cardiac involvement: Case report and review of the literature. Am J Kidney Dis 2009;54:e9-15. 